Abant Tıp Dergisi

Araştırma Makalesi / Cilt 10 Sayı 1 Yıl 2021
Abant Medical Journal

Research Article / Volume 10 Issue 1 Year 2021

\title{
Laparoskopik Apendektomi Taburculuk Sonrası Hastaneye Erken Dönem Plansız Geri Dönüşleri Azaltıyor mu?
}

Does Laparoscopic Apendectomy Reduce Readmission After Discharge?

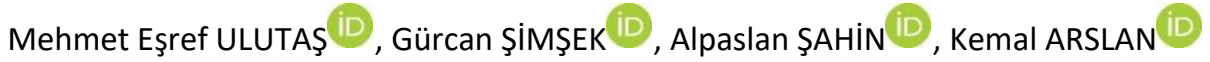 \\ Konya Eğitim ve Araştırma Hastanesi Genel Cerrahi Kliniği Meram, Konya - Türkiye
}

Öz

GiRiş ve AMAÇ: Akut apandisit cerrahi tedavi gerektiren en sık akut karın ağrısı nedenidir. Apendektomi sonrası ortalama geri dönüş oranı $\% 4,3$ olarak bildirilmiş ve laparoskopik apendektominin yaygınlaşmasının bu oranı azaltabileceği vurgulanmıştır. Bizim kliniğimizde de son yıllarda laparoskopik apendektomi gittikçe artmaktadır. Bu nedenle laparoskopik apendektomi sonrası geri dönüş oranını, geri dönüş nedenlerini araştırmayı amaçladık. Ayrıca konvansiyonel-açık apendektomi ile laparoskopik apendektomi arasında geri dönüş oranlarının karşılaştırılmasını amaçladık.

YÖNTEM ve GEREÇLER: Bu çalışma S.B.Ü Konya Eğitim ve Araştırma Hastanesi Genel Cerrahi Kliniğinde retrospektif olarak gerçekleştirildi. Ocak 2018 ve aralık 2019 tarihleri arasında kliniğimizde yapılan apendektomi vakaları belirlendi. Bu hastaların taburcu edildikten sonra ilk 30 gün içerisinde yatış gerektiren tekrar hastaneye başvuruları geri dönüş olarak kabul edildi. Hastalar laparoskopik ve konvansiyonel apendektomi yapılanlar olarak iki gruba ayrıldı. Gruplar geri dönüş oranları ve geri dönüşe yol açan komplikasyonlar açısından istatistiksel olarak kıyaslandı.

BULGULAR: Çalışmaya 897 hasta dahil edildi. Genel olarak apendektomi sonrası geri dönüş oranı $\% 2,8$ olarak bulundu. Laparoskopik apendektomi için geri dönüş oranı \%1,3 ve konvansiyonel apendektomi için geri dönüş oranı da \%3,6 bulundu. Konvansiyonel apendektomi ve laparoskopik apendektomi arasında geri dönüş oranları arasında istatistiksel olarak anlamlı fark yoktu. Yapılan logistik regresyon analizinde konvansiyonel apendektominin operasyon sonrası hastaneye erken dönem geri dönüş için bir risk faktörü olduğu tespit edildi. Laparoskopik apendektomi grubunda en sık geri dönüş nedeni cerrahi alan enfeksiyonuydu. Geri dönüş tespit edilen hastalarda ise reoperasyon oranı \%12'ydi. Bu hastaların tamamı konvansiyonel apendektomi grubunda olup laparoskopik apendektomi grubunda re-operasyon tespit edilmedi.

TARTIŞMA ve SONUÇ: Günlük genel cerrahi pratiğinde en sık yapılan ameliyatların başında gelen apendektominin geri dönüş oranını \%2,8 olarak tespit ettik ve bu oran literatürden düşüktü. Laparoskopik apendektomi grubunda geri dönüş oranı konvansiyonel apendektomiye göre oldukça düşük olmasına karşın istatistiksel fark tespit edilemedi. Apendektomi sonrası geri dönüşlerin en sık nedeni ise cerrahi alan enfeksiyonuydu. Laparoskopik apendektomi geri dönüş

\section{Abstract}

INTRODUCTION: Acute appendicitis is the most common cause of acute abdominal pain requiring surgical treatment. The average readmission rate after appendectomy was reported as $4.3 \%$ and it was emphasized that the common use of laparoscopic appendectomy may decrease this rate. In our clinic, laparoscopic appendectomy is being used more and more frequently in recent years. Therefore, we aimed to investigate the rate of readmission and the reasons after laparoscopic appendectomy. In addition, we aimed to compare the readmission rates between conventional-open appendectomy and laparoscopic appendectomy.

METHODS: This study was carried out retrospectively in the General Surgery Clinic of the S.B.Ü Konya Training and Research Hospital. Appendectomy cases performed in our clinic between January 2018 and December 2019 were determined. Among these patients, those who were hospitalized within 30 days after discharge were accepted as readmision. The patients were divided into two groups as those who underwent laparoscopic and conventional appendectomy. Groups were compared statistically in terms of rates of readmission and complications leading to readmission.

RESULTS: 897 patients were included in the study. Generally, the recovery rate after appendectomy was $2.8 \%$. The readmission rate for laparoscopic appendectomy was $1.3 \%$ and the readmission rate for conventional appendectomy was $3.6 \%$. There was no statistically significant difference in readmission rates between conventional appendectomy and laparoscopic appendectomy. In the logistic regression analysis performed, it was determined that conventional appendectomy is a risk factor for early return to the hospital after the operation. In the laparoscopic appendectomy group, the most common reason for return was surgical site infection. The re-operation rate was $12 \%$ in patients with readmission. All of these patients were in the conventional appendectomy group and no reoperation was detected in the laparoscopic appendectomy group.

DISCUSSION and CONCLUSION: We found the rate of readmission of appendectomy, which is one of the most common operations performed in daily general surgery practice, as $2.8 \%$, and this rate was lower than the literature. Although the rate of readmission in the 

than that of conventional appendectomy, no statistical difference was found. The most common reason for readmission after appendectomy was surgical site infection. Laparoscopic appendectomy is a safe method for readmission.

\section{GíRiş}

Akut apandisit $(A A)$ cerrahi tedavi gerektiren en sık akut karın ağrısı nedenidir1. Global Burden Study (2016) göre AA sıklığı 100.000 nüfusta yıllık 114,44-481,60 olarak bildirilmiştir. AA sıklığı sosoyo-kültürel düzey ile koreledir ve sanayileşmiş ülkelerde insidansın hızla arttığı da bildirilmektedir2. AA için standart tedavi yöntemi sağ alt kadran insizyonu ile yapılan konvansiyonel veya açık apendektomidir (KA). Bu yöntem yaklaşık 100 yıldan uzun süredir değişmeden uygulanmaya devam etmektedir3,4. Laparoskopik apendektomi (LA) ise son yıllarda giderek artan oranlarda uygulanmaktadır. LA' nin daha düşük postoperatif ağrı, daha düşük komplikasyon oranı, daha kısa hastanede kalış süresi gibi $K A^{\prime}$ den önemli üstünlükleri olduğu gösterilmiştir5.

Bir cerrahi tedavinin evrensel ölçülerde kalitesini belirlemede perioperatif komplikasyonlar ve hastanede kalış süreleri önemli kriterlerdir. Ayrıca geri kabul oranları da cerrahi tedavinin etkinliğini belirlenmesinde kabul gören bir kriterdir. Son yıllarda LA ve KA karşılaştıran randomize çalışmalar neticesinde $L A$ giderek $A A$ tedavisinde standart yaklaşım olma yolunda ilerlemektedir6. Kate Bailey ve ark. tarafından yapılan bir meta-analizde apendektomi sonrası ortalama geri dönüş oranı $\% 4,3$ olarak bildirilmiş ve LA' nin yaygınlaşmasının bu oranı azaltabileceği vurgulanmıştır7. Bizim kliniğimizde de son yıllarda LA gittikçe artmaktadır. Bu nedenle LA sonrası geri dönüşleri araştırmak istedik.

Çalışmamızda LA ve KA ameliyatı yapılan hastaların geri dönüş oranları ve geri dönüş nedenleri karşılaştırılarak $\mathrm{LA}^{\prime}$ nin geri dönüş üzerinde azaltıcı bir etkisi olup olmadığının belirlenmesi amaçlanmıştır.

\section{GEREÇ ve YÖNTEMLER}

Bu çalışma S.B.Ü Konya Eğitim ve Araştırma Hastanesi Genel Cerrahi Kliniğinde retrospektif olarak gerçekleştirildi. Hastane kayıtlarını kullanmak için hastanemiz TUEK' dan onam alınmıştır. Ocak 2018 ve Aralık 2019 tarihleri arasında kliniğimizde yapılan apendektomi vakaları belirlendi. $\mathrm{Bu}$ hastaların taburcu edildikten sonra ilk 30 gün içerisinde yatış gerektiren tekrar hastaneye başvuruları geri dönüş olarak kabul edildi. Hastanemiz sisteminde geri dönüş belirlenmeyen vakalar ise telefon ile aranarak " ameliyat sonrasında 1 ay içerisinde herhangi bir hastanede yatarak tedavi olupolmadıkları" soruldu.

Hastaların ameliyat şekilleri ve operasyon sonrası yatış süreleri tespit edildi. Geri dönüş tespit edilen hastaların da geri dönüş nedenleri, geri dönüşler için yapılan tedavi yöntemleri ve hastaların geri dönüş sonrası yatış süreleri belirlendi.

KA klasik Mc-Burney insizyon ile genel anestezi veya spinal anestezi altında gerçekleştirildi. KA vakalarında apendiküler arter ve apendiks güdüğü ipek ile bağlandı.LA de ise sol alt kadrandan ve umblikus üzerinden 2 adet $10 \mathrm{~mm}$ ve suprapubik 1 adet $5 \mathrm{~mm}$ lik trokar kullanılarak gerçekleştirildi. Apendiküler arter ligasure ile bağlanıp apendiks güdüğü için hemo-klip kullanıldı. KA ve LA vakalarında rutin olarak dren kullanılmamaktadır.

Tüm veriler SPSS programına kaydedildi. Hastalar 
laparoskopik ve konvansiyonel apendektomi olarak iki gruba ayrıldı. Gruplar komplike olan ve olmayan vakalar açısından heterojendi. Gruplar geri dönüş oranları ve geri dönüşe yol açan komplikasyonlar istatiksel olarak kıyaslandı. $\mathrm{P}$ değerinin $0,05^{\prime}$ den düşük olması anlamlı kabul edildi. Ayrıca LA için lojistik regresyon analizi ile risk analizi yapıldı.

\section{YÖNTEM}

Bu çalışma S.B.Ü Konya Eğitim ve Araştırma Hastanesi Genel Cerrahi Kliniğinde retrospektif olarak gerçekleştirildi. Hastane kayıtlarını kullanmak için hastanemiz TUEK' dan onam alınmıştır. Ocak 2018 ve Aralık 2019 tarihleri arasında kliniğimizde yapılan apendektomi vakaları belirlendi. $\mathrm{Bu}$ hastaların taburcu edildikten sonra ilk 30 gün içerisinde yatış gerektiren tekrar hastaneye başvuruları geri dönüş olarak kabul edildi. Hastanemiz sisteminde geri dönüş belirlenmeyen vakalar ise telefon ile aranarak " ameliyat sonrasında 1 ay içerisinde herhangi bir hastanede yatarak tedavi olupolmadıkları" soruldu.

Hastaların ameliyat şekilleri ve operasyon sonrası yatış süreleri tespit edildi. Geri dönüş tespit edilen hastaların da geri dönüş nedenleri, geri dönüşler için yapılan tedavi yöntemleri ve hastaların geri dönüş sonrası yatış süreleri belirlendi.

KA klasik Mc-Burney insizyon ile genel anestezi veya spinal anestezi altında gerçekleştirildi. KA vakalarında apendiküler arter ve apendiks güdüğü ipek ile bağlandı. LA de ise sol alt kadrandan ve umblikus üzerinden 2 adet $10 \mathrm{~mm}$ ve suprapubik 1 adet $5 \mathrm{~mm}$ lik trokar kullanılarak gerçekleştirildi. Apendiküler arter ligasure ile bağlanıp apendiks güdüğü için hemo-klip kullanıldı. KA ve LA vakalarında rutin olarak dren kullanılmamaktadır.

Tüm veriler SPSS programına kaydedildi. Hastalar laparoskopik ve konvansiyonel apendektomi olarak iki gruba ayrıldı. Gruplar komplike olan ve olmayan vakalar açısından heterojendi. Gruplar geri dönüş oranları ve geri dönüşe yol açan komplikasyonlar istatiksel olarak kıyaslandı. P değerinin $0,05^{\prime}$ den düşük olması anlamlı kabul edildi. Ayrıca LA için lojistik regresyon analizi ile risk analizi yapıldı.

\section{BULGULAR}

Ri Ocak 2018 ve Aralık 2019 tarihleri arasında kliniğimizde 982 adet AA nedeni ile apendektomi yapıldığı tespit edildi. Bu hastalardan 85 tanesi; kayıtları çalışma verilerini karşılamadığı veya hastalarla telefon ile irtibat kurulamadığı için çalışma dışı bırakıldılar.

Çalışmamızda 897 hasta değerlendirilmiştir. Hastaların ortalama yaş değeri $31,62 \pm 14,16$ olarak bulundu. Hastaların \%62,9 ( $n=564)$ erkek ve $\% 37,1$ ( $n=333$ ) kadındı. Vakaların 307' sine $(\% 34,2)$ LA ve 590'ına $(\% 65,8)$ KA uygulandığı tespit edildi (Tablo.1).

Tüm hastalar içerisinde geri dönüş oranı $\% 2,8$ $(n=25)$ olarak tespit edildi. LA grubunda geri dönüş oranı \%1,3 $(n=4)$ ve KA grubunda ise \%3,6 $(n=21)$ olarak tespit edildi. Grupların geri dönüş oranlarının kıyaslanması neticesinde istatiksel olarak anlamlı fark bulunmadı ( $p: 0,052)$. LA grubunda hastanede yatış süresi ortalama $2,63 \pm 1,90$ gün olarak bulunurken KA grubunda bu sürenin $2,65 \pm 1,69$ gün olduğu tespit edilmiş ve grupların hastanede kalış süreleri arasında anlamlı fark tespit edilmemiştir ( $p: 0,349$ ). Geri dönüş tespit edilen hataların ikinci yatışları ise $L A$ grubunda $5,75 \pm 1,5$ gün ve $K A$ grubunda da $5,62 \pm 5,67$ gün olarak hesaplandı. İkinci yatışların istatiksel olarak kıyaslanması neticesinde de anlamlı fark tespit edilmedi ( $p: 0,054)$. Hastaların demografik özellikleri, operasyon şekilleri ve geri dönüş oranları Tablo.1' de detaylı olarak görülmektedir.

Yapılan logistik regresyon analizinde KA'nin operasyon sonrası hastaneye erken dönem geri dönüş için bir risk faktörü olduğu tespit edilmiştir (OR:2,79). 
Geri dönüş tespit edilen vakaların geri dönüş nedenleri değerlendirildiğinde en sık geri dönüş nedeni \%52 ( $n=13$ ) ile cerrahi alan enfeksiyonu (CAE) olarak tespit edildi. LA grubunda CAE nedeni ile geri dönüş oranı $\% 75$, KA grubunda ise $\% 47,6$ olarak tespit edildi. Gruplar arasında CAE bağlı geri dönüş oranları arasında istatistiksel fark bulunmadı ( $p: 0,409$ ). CAE bağlı geri dönüşler detaylandırıldığında yüzeyel CAE bağıı geri dönüş oranı tüm hastalarda \%28 $(n=7)$ olarak bulunurken KA grubunda bu oran $\% 33,3$ olarak tespit edildi.LA grubunda yüzeyel CAE görülmemiştir. LA ve KA gruplarının yüzeyel CAE bağlı geri dönüş oranları arasında istatiksel fark yoktu ( $p: 0,331)$. Geri dönüş tespit edilen hastalar içerisinde derin CAE bağıı geri dönüş oranı \%28 $(n=7)$ olarak bulundu. LA grubunda geri dönüş tespit edilen vakalarda derin CAE oranı \%75' di. Bu oran KA grubunda ise $\% 19$ olarak tespit edildi. Geri dönüş tespit edilen vakalarda derin CAE oranlarının istatistiksel kıyaslanması neticesinde fark görülmedi ( $p: 0,081)$.

Geri dönüş tespit edilen hastalarda ikinci en sık neden $\% 16(n=4)$ ileus olarak tespit edildi. LA grubunda geri dönen hastalar içerisinde ileus oranı \%25; KA grubunda ise aynı oran \%14,3 olarak tespit edildi. LA ve KA gruplarında geri dönüş tespit edilen vakalarda ileus görülme oranlarının istatistiksel kıyaslanmasında fark yoktu (p: 0,748).

Geri dönüş tespit edilen vakalarda diğer tespit edilen nedenler spinal anestezi sonrası baş ağrısı veya dura ponksiyonuna bağlı baş ağrısı sıklığı $\% 12(n=3)$ olarak tespit edilmiştir. Bu hastaların tamamı KA grubunaydı. LA grubunda spinal anestezi ile operasyon yapılmadığı için bu parametre için istatistiksel analiz yapılmadı. Geri dönüş olan hastalarda belirlenen diğer bir neden de non-spesifik karın ağrısı olup tüm geri dönüş hastalarında görülme oranı $\% 12 \quad(n=3)$ olarak bulundu. Bu hastaların tamamı KA grubundaydı. Non-spesifik karın ağrısı açısından KA ve LA gruplarının kıyaslanması neticesinde fark tespit edilmedi (0,695). Geri dönüş tespit edilen vakalarda geri dönüş nedenleri ve gruplara göre dağılımı tablo.2' de görülmektedir.

Geri dönüş tespit edilen hastaların tedavi şekilleri de değerlendirildi. Tedavi metodları cerrahi tedavi (re-operasyon), medikal tedavi ve görüntüleme eşliğinde yapılan perkutan işlemler olarak 3 ana grupta değerlendirildi. Tüm hastalar içerisinde re-operasyon oranı $\% 0,33(n=3)$ olarak tespit edildi. Geri dönüş tespit edilen hastalarda ise re-operasyon oranı \%12 ( $n=3)$. Bu hastaların tamamı KA grubunda olup LA grubunda reoperasyon tespit edilmedi. KA ve LA gruplarında geri dönüş tespit edilen hastaların re-operasyon oranları kıyaslandığında istatistiksel fark tespit edilmedi ( $p: 0,695$ ). Geri dönüş tespit edilen hastaların tedavi yöntemleri tablo.3'de özetlenmiştir.

Apendektomi sonrası geri dönüş tespit edilen hastaların tedavisinde en sık yöntem medikal tedavi olarak tespit edildi. Geri dönüş tespit edilen 25 hastanın \% 72'si ( $n=18)$ medikal olarak tedavi edildi. Medikal tedavi oranı LA sonrası geri dönen hasta grubunda $\% 60(n=3)$ ve KA grubunda ise \%71,4 $(n=15)$ olarak bulundu. Grupların medikal tedavi oranları arasında fark yoktu ( $p$ : $0,915)$. Geri dönen hasta grubunda diğer bir tedavi yöntemi USG eşliğinde drenajdı. Tüm geri dönen hastalarda USG ile drenaj yöntemi ile tedavi edilen hasta oranı \% $16 \quad(n=4)$ olarak bulundu. LA sonrası geri dönüşlerin $\% 25^{\prime} i$ ve KA sonrası geri dönüşlerin de $\% 14,3$ 'ü perkutan drenaj yöntemi ile tedavi edilmişti. LA ve KA sonrası geri dönen hastaların tedavi yöntemlerinde perkutan drenaj metodu ile tedavi oranları arasında fark tespit edilmedi ( $p: 0,543)$.

\section{TARTIŞMA}

Bu AA cerrahların günlük pratiğinde oldukça sık karşılaştıkları bir problemdir. AA sıklığı yaşam boyunca yaklaşık \%7, 5' tir8. Apendektomi sonrası geri dönüş ciddi maliyet artışına neden olmaktadır. Bu nedenle geri dönüş oranlarının net olarak belirlenmesi ve bu oranı aşağı çekecek uygulamaların tanımlanmasına ihtiyaç vardır9,10. 
Bu ihtiyaç nedeni ile çok sayıda çalışma yapılmış ve nihayetinde meta-analizler ve geniş Kohort serileri de ortaya konulmuştur. Kate Bailey ve ark. tarafından yapılan bir meta-analizde apendektomi sonrası ortalama geri dönüş oranı

Tablo 1. Grupların demografik özellikleri, geri dönüş oranları, yatış sürelerinin analizi

\begin{tabular}{|c|c|c|c|c|}
\hline & Tüm Hastalar & LA $(n=307)$ & $K A(n=590)$ & p \\
\hline Yaş ortalama & $31,62 \pm 14,16$ & $35,75 \pm 25,1$ & $30,33 \pm 15,32$ & 0,827 \\
\hline Yaş Medyan & 27 & 27 & 27 & - \\
\hline Erkek & $\% 62,9 \quad(n=564)$ & $\% 59,9(n=184)$ & $\% 64,4(n=380)$ & \multirow{2}{*}{0,189} \\
\hline Kadın & $\% 37,1(n=333)$ & $\% 40,1(n=123)$ & $\% 35,6(n=210)$ & \\
\hline Geri Dönüş Oranı & $\% 2,8(n=25)$ & $\% 1,3(n=4)$ & $\% 3,6(n=21)$ & 0,052 \\
\hline $\begin{array}{l}\text { İlk ameliyat ortalama yatış } \\
\text { süresi }\end{array}$ & $2.64 \pm 1,76$ & $2,63 \pm 1,90$ & $2,65 \pm 1,69$ & 0,349 \\
\hline $\begin{array}{l}\text { Tekrar başvuru ortalama } \\
\text { yatış süresi }\end{array}$ & $5,64 \pm 5,20$ & $5,75 \pm 1,5$ & $5,62 \pm 5,67$ & 0,054 \\
\hline
\end{tabular}

Tablo 2. Geri dönüş tespit edilen vakalarda geri dönüş nedenleri ve gruplara göre dağılımı

\begin{tabular}{lccc}
\hline Geri Dönüş Nedenleri & LA (n:4) & KA (n:21) & p \\
\hline CAE & $\% 75(n: 3)$ & $\% 47,6(n: 10)$ & 0,331 \\
Yüzeyel CAE & $\% 0(n: 0)$ & $\% 33,3(n=7)$ & 0,081 \\
Derin CAE & $\% 75(n=3)$ & $\% 19(n=4)$ & 0,748 \\
Illeus & $\% 25(n=1)$ & $\% 14,3(n=3)$ & - \\
Spinal Anestezi Sonrası Başağrısı & $\% 0(n: 0)$ & $\% 14,3(n=3)$ & 0,695 \\
Non-Spesifik Karın Ağrısı & $\% 0 \quad(n: 0)$ & $\% 14,3(n=3)$ & \\
\hline
\end{tabular}

Tablo 3. Geri dönüş tespit edilen vakalarda tedavi yöntemleri ve gruplara göre dağılımı

\begin{tabular}{lccc}
\hline Geri Dönüşlerde Tedavi & LA (n=4) & KA (n=21) & 0,915 \\
\hline Medikal Tedavi & $\% 75(n: 3)$ & $\% 71,4(n: 15)$ & 0,543 \\
USG eşliğinde drenaj & $\% 25(n: 1)$ & $\% 14,3(n: 3)$ & 0,695 \\
Re-operasyon & $\% 0(n: 0)$ & $\% 14,3(n: 3)$ & \\
\hline
\end{tabular}


$\% 4,3$ olarak bildirilmiş ve LA ile azalmış geri dönüş oranı arasında ilişki olduğu vurgulanmıştır. Bu meta-analizde değerlendirmeye alınan çalışmalarda geri dönüş oranı $\% 4,2-4,3$ aralığındaydı. Yine aynı analizde 18 yaş üstü hastaları içeren çalışmalarda ortalama geri dönüş oranı $\% 4,6(\% 1,4-6,3) 18$ yaş altı popülasyonda ise ortalama geri dönüş oranı $\% 4$ (\%0-14,4)'tü7. 46.960 hastayı içeren ve yaklaşık \%80 vakaya LA uygulanan retrospektif bir analizde erişkinlerde apendektomi sonrası geri dönüş oranı $\% 3,7$ olarak tespit edilmiştir. Bu çalışmada geri dönüş tespit edilen hastaların $\% 83,8^{\prime}$ ine LA uygulanmıştı11. Çalışmamızda 897 apendektomi sonrası geri dönüş oranı $\% 2,8$ olarak tespit edildi. Geri dönüş tespit edilen hastaların ise $\% 16$ 'sına LA uygulanmıştı. Bu veriler ışığında çalışmamızda tespit edilen $\% 2,8^{\prime}$ lik geri dönüş oranı düşük olarak görülmektedir. Özellikle LA sonrası \%1, $6^{\prime}$ lık geri dönüş oranı literatürden oldukça düşüktür.

LA uygulanan ve 4618 hastayı içeren geniş bir multisentrik kohort analizinde geri dönüş oranı $\% 2,56$ olarak bulunmuştur6. Bizim çalışmamızda ise 897 hastadan 307' sine LA uygulanmıştı ve LA sonrası geri dönüş oranı $\% 1,3$ olarak tespit edilmiştir. KA sonrası geri dönüş oranı ise $\% 3,6$ olarak bulundu. KA ve LA sonrası geri dönüş oranları açısından yaklaşık 3 kata yakın bir fark tespit edilmiştir. Ancak yapılan analizde istatistiksel fark tespit edilmemiştir. Ayrıca KA'nin geri dönüş açısından risk faktörü olarak değerlendirildiği logistik regresyon analizi sonucunda OR:2,79 ve $\mathrm{p}$ : 0,062 olarak tespit edildi. Moghadamyeghaneh $Z$ ve arkadaşları tarafından yapılan retrospektif analizde hastaların çoğuna LA uygulanmış ve LA vakalarından sonra tekrar hastaneye geri dönüş oranı KA' den belirgin düşük bulunmuştur. Bizim çalışmamızda istatistiksel fark olmamasını LA oranımızın düşük olmasına bağlayabiliriz.

Apendektomi sonrası geri dönüşlerin en sık nedeni enfeksiyonlar ve non-spesifik karın ağrısı olarak tespit edilmiştir. Bu çalışmada taburcu edildikten sonra ki 30 gün içerisinde geri dönüş nedenleri; \%27,3 intraabdominal enfeksiyonlar, $\% 7,9$ non-spesisfik karın ağrısı ve $\% 4,6$ paralitik ileus olarak sıralanmaktadır11. Bizim çalışmamızda geri dönüşlerin $\% 52^{\prime}$ si CAE bağııdı. Derin CAE bağlı geri dönüş oranı ise \%28 olarak bulundu. Derin CAE sıklığı literatürle örtüşmektedir. Yüzeyel CAE bağlı geri dönüşlerin tamamının KA grubunda olması LA' nin üstünlüğü olarak öngürülebilir. Çalışmamızda tespit edilen \%12'lik non-spesifik karın ağrısı oranı literatüre göre yüksek olup bu hastaların tamamı KA grubundaydı. Bu durum literatürden farklılık göstermeketedir. Çünkü Moghadamyeghaneh Z ve arkadaşları tarafından yapılan retrospektif analizde non-spesifik karın ağrısı LA grubunda daha sıktır11. Çalışmamızda tespit edilen ileusa bağlı geri dönüş oranı \%16 olup bu hastaların çoğu KA grubundaydı.

Spinal anestezi altında opere edilen hastalarda görülen bir komplikasyon olan şiddetli baş ağrısı, başka bir ifade ile dura ponksiyonu sonrası baş ağrısı, dural yırtıktan BOS sızıntısı ve BOS basıncının düşmesi neticesinde gelişir. Dura ponksiyonu sonrası başağrısı, spinal anestezinin en sık karşılaşılan komplikasyonlarından biridir. Dura ponksiyonu sonrası başağrısı, genellikle fronto-occipital bölgede, bilateral, zonklayıcı olmayan, ayakta durmakla artan ve yatar pozisyonda azalan karakter göstermektedir. Genellikle 24 saat içinde başlar ve beraberinde bulantı-kusma, baş dönmesi, işitme kaybı, hiperakuzi, tinnitus, fotofobi, diplopi, boyunda sertlik ve skapular ağrı olabilir12,13. Hastanemizde KA uygulanan vakalarda spinal anestezi yöntemi oldukça sık tercih edilmektedir. Dolayısı ile hastalarımızda taburcukuk sonrası bağ ağrısı sık görülen bir problem olmaktadır. Çalışmamızda spinal anestezi komplikasyonuna bağlı geri dönüş oranı tüm geri dönüşlerin \%12'sini teşkil ediyordu. Literatürde apendektomi sonrası geri dönüşleri içeren serilerde bu komplikasyona rastlamadık. Bunun nedeni KA' nin oldukça düşük oranlarda olması ve $K A^{\prime}$ nin daima genel anestezi altında yapılması olabilir. LA grubunda hiçbir hasta spinal anestezi 
altında ameliyat edilmediği için bu komplikasyonun gruplar arası istatistiksel analizini yapamadık. Her ne kadar anestezi komplikasyonu da olsa ameliyatın bir komplikasyonu olduğunu düşündüğümüz için dura ponksiyonu sonrası baş ağrısını da apendektomi sonrası hastaneye geri dönüş nedeni olarak değerlendirdik.

Çalışmamızın en önemli sınırlayıcı özelliklerinin LA oranının düşük olması, grupların komplike olan ve olmayan vakalar açısından homojen olmaması, perfore olan ve olmayan vakaların ayrıştırılmaması olduğunu söyleyebiliriz. Özellikle LA oranının artması ile LA ve KA arasında geri dönüş oranları arasında tespit ettiğimiz aritmetik farkın anlamlı olacağı kanısındayız.

Sonuç olarak; cerrahların günlük pratiklerinde en sık icra ettikleri ameliyatların başında gelen apendektominin geri dönüş oranını $\% 2,8$ olarak tespit ettik ve bu oran literatürden düşüktü. LA grubunda geri dönüş oranı KA göre oldukça düşük olmasına karşın istatistiksel fark tespit edilemedi. Apendektomi sonrası geri dönüşlerin en sık nedeni ise CAE'dur. LA geri dönüş açısından güvenli bir yöntem olabileceği düşünülebilir.

Bilgilendirilmiş Onam: Katılımcılardan yazılı onam alınmıştır.

Çıkar Çatışması: Yazarlar çıkar çatışması beyan etmemişlerdir.

Finansal Destek: Yazarlar finansal destek beyan etmemişlerdir.

\section{KAYNAKLAR}

1. Graffeo CS, Counselman FL. Appendicitis. Emerg. Med.Clin. North Am.1996; 14: 653-71.

2. Ferris, M. et al. The Global Incidence of Appendicitis: A Systematic Review of Population-based Studies. Ann Surg. 266(2), 237-41 (2017).

3. Sartelli, M. et al. The management of intra-abdominal infections from a global perspective: 2017 WSES guidelines for management of intra-abdominal infections. World J Emerg Surg. 12(1), 29 (2017).

4. Poon, S. H. T. et al. The current management of acute uncomplicated appendicitis: should there be a change in paradigm? A systematic review of the literatures and analysis of treatment performance. World J Emerg Surg. 12, 46 (2017).

5. Li, X. et al. Laparoscopic versus conventional appendectomy-a meta-analysis of randomized controlled trials. BMC Gastroenterol.10, 129 (2010).

6. Waledziak M, Lasek $A$, Wysocki $M$, et all. Risk factors for serious morbidity, prolonged length of stay and hospital readmission after laparoscopic appendectomy - results from Pol-LA (Polish Laparoscopic Appendectomy) multicenter large cohort study Sci Rep. 2019 Dec 6;9(1):18479.

7. Bailey K, Choynowski M, Mohammad S, et al. Metaanalysis of unplanned readmission to hospital postappendectomy: an opportunity for a new benchmark. ANZ J Surg. 2019 Nov;89(11):1386-1391.7

8. Vissers RJ, Lennarz WB. Pitfalls in appendicitis. Emerg. Med. Clin. North Am. 2010; 28: 103-18.

9. Sugrue $M$, Maier R, Moore EE et al. Proceedings of resources for optimal care of acute care and emergency surgery consensus summit Donegal Ireland. World J. Emerg. Surg. 2017; 12: 47.

10. Nathan H, Dimick JB. Quality accounting. Ann. Surg. 2017; 265:1051-2.

11. Moghadamyeghaneh Z, Hwang G, Hanna MH, et all. Unplanned readmission after appendectomy. Am J Surg. 2016 Sep;212(3):493-500.

12. Apfel CC, Saxena A, Çakmakkaya OS, et al. Prevention of postdural puncture headache after accidental dural puncture: a quantitative systematic review. $\mathrm{Br} \mathrm{J}$ Anaesth 2010;105(3):255-63.

13. Agarwal A, Kishore K. Complications And Contraversies Of Regional Anaesthesia: A Review. Indian J Anaesth 2009;53(5):543-53. 